\title{
A visão de estudantes de licenciaturas sobre o uso de vídeo na formação docente
}

\section{The inspection of undergraduate students on the use of video in teacher education}

\section{Samira Bahia e Castro ${ }^{1}$, Silvana Claudia dos Santos $^{2}$}

RESUMO: Esse artigo é fruto de uma pesquisa que investigou, a partir das perspectivas de estudantes de licenciaturas de uma Universidade Federal mineira, como o vídeo tem sido utilizado enquanto recurso didático na formação docente. Partimos do princípio que o vídeo consiste em um recurso que pode despertar a criatividade, o interesse e favorecer diferentes dimensões cognitivas de estudantes em contextos educacionais diversos, podendo vir a assumir um papel relevante nos processos de ensino e aprendizagem. Para fins de produção de dados, foram realizadas entrevistas semiestruturadas com grupos de estudantes dos cursos de licenciatura em Pedagogia, História e Letras, visando identificar as visões desses futuros professores em relação ao uso de recursos audiovisuais na sua formação docente. Como resultados, obtivemos que os estudantes entendem que este tipo de tecnologia digital pode potencializar a aprendizagem, porém não se reconhecem totalmente preparados para utilizá-la na futura prática como docentes e sentem falta de uma formação específica que aborde sobre a produção e a utilização dessa tecnologia no ensino. Assim, esse estudo se mostrou importante, uma vez que ofereceu elementos que contribuem com o debate atual acerca do uso do vídeo e das tecnologias digitais, em geral, na Educação.

PALAVRAS-CHAVE: Metodologias de ensino; Formação inicial de professores; Recursos audiovisuais.

\begin{abstract}
This article is the result of a research that investigated the perspective of undergraduate students at the Federal University of Minas Gerais on how video has been used as a didactic resource in teacher education. We assume that video is a resource that can sharpen creativity, interest, and enhance different cognitive dimensions of students in different educational contexts. And it may undertake a relevant role in teaching and learning processes. For purpose of data production, semi-structured interviews were carried out with groups of students from undergraduate courses in Pedagogy, History, and Language. Aiming to identify the inspection of these future teachers about the use of audiovisual resources in their teacher training. As a result, we obtained that students understand that this type of digital technology can improve learning, but they do not recognize themselves as fully prepared to use it in future practice as teachers and they miss a specific training that

\footnotetext{
${ }^{1}$ Licenciada em Pedagogia e Mestra em Educação pela Universidade Federal de Viçosa - UFV. Membro do Grupo de Atenção às Tecnologias na Educação - GATE da UFV. ORCID: https://orcid.org/0000-0003-2677-2888. E-mail: samirabahia@yahoo.com.br.

${ }^{2}$ Licenciada em Matemática pelo CEFET-PR em Pato Branco-PR, Mestra e Doutora em Educação Matemática pela UNESP de Rio Claro/SP. Docente do Departamento de Educação da Universidade Federal de Viçosa - UFV atuando, também, no Programa de Pós-graduação em Educação (PPGE) e no Programa de Pós-graduação em Educação em Ciências e Matemática (MPECM) desta instituição. Coordenadora do Grupo de Atenção às Tecnologias na Educação GATE da UFV. Membro associada do Grupo de Pesquisa em Informática, outras Mídias e Educação Matemática GPIMEM da UNESP. ORCID: https://orcid.org/0000-0002-5727-9191. E-mail: silvana.santos@ufv.br.
}

Agradecimento à Fundação de Amparo à Pesquisa do Estado de Minas Gerais (FAPEMIG) pela bolsa concedida. COLÉGIO DE APLICAÇÃO-COLUNI / UNIVERSIDADE FEDERAL DE VIÇOSA https://periodicos.ufv.br/rpv 
addresses the production and use of this technology in teaching. Thus, this study showed to be important, meanwhile, it offered elements that contribute to the current discussion about the use of video and digital technologies in Education.

KEYWORDS: Teaching methodologies; Initial teacher training; Audiovisual resources.

\section{INTRODUÇÃO}

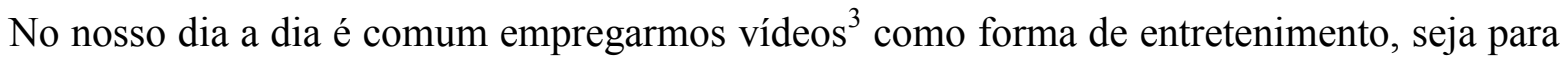
relaxar, passar o tempo ou se divertir. No entanto, essa tecnologia possui potencialidades diversas, podendo ser utilizada, também, como instrumento educacional. De acordo com Silva e Oliveira (2010), os recursos midiáticos podem auxiliar no desenvolvimento da criatividade; permitem tratar de diferentes conteúdos; além de poderem atingir as emoções das pessoas. Assim, eles podem favorecer o desenvolvimento do pensamento e os processos de ensino e de aprendizagem.

Porém, segundo Castro (2020), no decorrer dos anos escolares muitos professores, em especial os da educação básica, fazem uso limitado das tecnologias digitais, o que inclui o uso de vídeos com fins pedagógicos, alegando a falta de estrutura das escolas e a dificuldade em planejar seu uso. Além disso, afirmam que muitos alunos veem essa tecnologia como um recurso empregado por docentes que não querem ministrar a aula.

Acreditamos que a temática sobre o uso de vídeo como recurso didático na formação de professores consiste em algo que merece um debate mais profícuo, que elucide a compreensão que docentes e futuros educadores têm acerca do uso desse recurso, sobretudo, se pensarmos no uso recorrente de tecnologias digitais em diferentes contextos.

Dessa forma, este artigo é um recorte de uma pesquisa (CASTRO, 2018), no qual buscamos evidenciar, a partir do ponto de vista de estudantes de cursos de licenciatura de uma Universidade Federal mineira, como o vídeo tem sido empregado, enquanto recurso didático, na formação desses futuros professores. Sendo assim, lançamos luz a essa questão, de modo a subsidiar as discussões sobre essa temática que se mostra cada vez mais atual, principalmente se considerarmos o acesso a smartphones ${ }^{4}$ e suas possibilidades de gravação de vídeos, bem como o seu compartilhamento via Internet, sobretudo, nas redes sociais.

Acreditamos que dificilmente um professor adotará determinada abordagem pedagógica ou utilizará certos recursos didáticos se não lhe for proporcionado a vivência ao longo da sua

\footnotetext{
${ }^{3}$ Ao longo deste texto, utilizaremos a expressão "vídeo" para nos referirmos a qualquer recurso audiovisual, de modo a não fazermos diferenciações entre filme e vídeo, por exemplo.

${ }^{4} \mathrm{O}$ termo smartphone pertence à língua inglesa e faz referência àquilo que, no nosso idioma, conhecemos como telefone inteligente. Trata-se de um telemóvel que oferece funções semelhantes às de um computador e que se destaca pela sua conectividade (FONTE: <https://conceito.de/smartphone>. Acesso em 18/04/2020).
} 
formação, uma vez que tendemos a repetir, e aprimorar ou adaptar, certas práticas e metodologias em nossa atuação profissional. Castro (2020, p. 67) corrobora essa ideia e complementa que "futuros professores que tiveram experiências com o uso de tecnologias para o ensino, tendem a se sentir melhor formados para utilizá-los futuramente". Portanto, investigar o modo como esse recurso vem sendo utilizado nos cursos de licenciatura, poderá oferecer subsídios para compreendermos o papel desse recurso na formação de professores, bem como identificar o seu potencial didático-pedagógico, com vistas a uma formação docente que privilegie boas práticas de uso do vídeo na educação.

\section{O VÍDEO NA EDUCAÇÃO}

Atualmente, uma das discussões que permeiam o ambiente educacional diz respeito a como despertar o interesse dos alunos pelas aulas e como favorecer a sua aprendizagem, visto que os estudantes não são todos iguais e cada um deles possui uma ou mais maneiras de aprender: alguns compreendem melhor escrevendo, outros lendo, outros ouvindo e outros vendo. Dessa forma, é importante que os docentes utilizem diferentes aportes metodológicos, visando potencializar a cognição dos alunos no intuito de favorecer a produção de conhecimentos.

Nesse sentido, os recursos midiáticos, em especial o vídeo, têm sido considerados uma alternativa ao trabalho docente, uma vez que o estudante emprega mais de um sentido quando o está assistindo, podendo, inclusive, fazer anotações ao decorrer do mesmo, ou seja, o vídeo pode se mostrar como um potencializador da aprendizagem. De acordo com Silva e Oliveira (2010, p. 1) esse recurso "[...] possibilita o despertar da criatividade à medida que, estimula a construção de aprendizados múltiplos, em consonância com a exploração da sensibilidade e das emoções dos alunos, além de contextualizar conteúdos variados", e de "[...] agregar conhecimentos diversos à temática a ser discutida, bem como a socialização dinâmica do ato de aprender" (SILVA; OLIVEIRA, 2010, p. 5).

Esse pensamento é compartilhado por Santos e Kloss (2010, p. 6) e por Moran (1995). Os primeiros afirmam que a partir do vídeo "[...] podem-se conhecer línguas, outras culturas, outros povos, sendo um meio de aprender de uma maneira que pode se tornar prazerosa, só pelo fato de ser diferente do que se realizam todos os dias". O segundo autor, por sua vez, complementa essa ideia argumentando que o vídeo está diretamente associado à televisão e, assim, os estudantes podem assumir uma postura diferente perante a ele, uma vez que a TV está presente no cotidiano da maioria das pessoas, sendo algo comum para os alunos. Logo, o vídeo se apresenta como um 
recurso didático familiar para os estudantes, o que pode fazer com que eles se identifiquem com seu uso. Além disso, esse recurso

[...] parte do concreto, do visível, do imediato, próximo, que toca todos os sentidos. Mexe com o corpo, com a pele - nos toca e "tocamos" os outros, estão ao nosso alcance através dos recortes visuais, do close, do som estéreo envolvente. Pelo vídeo sentimos, experienciamos sensorialmente o outro, o mundo, nós mesmos. (MORAN, 1995, p. 27)

Nessa mesma direção, Betetto (2011) afirma que os vídeos estão próximos da realidade do aluno e, assim, se aproximam com mais naturalidade do seu cotidiano, podendo resultar em uma aprendizagem significativa.

Porém, mesmo o vídeo se apresentando como um possível potencializador da aprendizagem, é preciso que o professor saiba utilizar esse recurso. De acordo com Betetto (2011, p. 28), "O uso do vídeo não pode ser resumido no sentido de proporcionar novidades e diversidades nas aulas. Sua utilização e estruturação devem ser pensadas como uma ferramenta para uso didático". Para a autora, ele não deve ser empregado como "tapa buraco" ou "enrolação", ou seja, para apenas preencher o horário da aula. Também não deve ser utilizado em todas as aulas, pois seu uso exagerado pode ser visto de maneira banal e causar um efeito contrário ao desejado. Além disso, não é recomendável que o vídeo seja simplesmente exibido ao aluno, pois é importante que ocorra uma discussão sobre ele (MORAN, 1995).

Moran, Masetto e Behrens (2006) apontam que o ensino ainda desvaloriza a utilização do vídeo para promover o aprendizado. Silva (2000) também discute essa questão, apontando que o seu uso em sala de aula já acumula uma série de críticas, pois, geralmente a sua utilização está associada ao lazer e ao entretenimento. Muitos professores costumam utilizar o vídeo fora de um contexto educacional, sem fins didáticos, e nem sempre as suas potencialidades pedagógicas são exploradas de maneira aprofundada.

No entanto, Serafim e Sousa (2011) afirmam que, apesar do vídeo ser visto como algo ligado ao lazer, a sua utilização em sala de aula, como recurso didático, possui um amplo potencial educacional que pode ser explorado pelo docente. Nessa mesma perspectiva, Moran (1995, pp. 3031) afirma que o vídeo pode ser interessante para introduzir um novo assunto, para despertar a curiosidade e a motivação para novos temas, o que pode fomentar o desejo de pesquisa nos alunos para aprofundar o assunto do vídeo e do conteúdo a ser trabalhado com os estudantes. Dessa forma, ele sugere diferentes modos de se utilizar o vídeo em sala de aula, sendo elas:

- Vídeo como sensibilização - para introduzir um novo tema, despertando a curiosidade e o interesse dos alunos. Podem ser utilizados vídeos curtos, propagandas, resenhas ou pequenos documentários, por exemplo; 
- Vídeo como ilustração - para exemplificar um assunto, aproximar o que se está estudando à realidade dos alunos. Aqui, podem ser usados filmes, entrevistas ou documentários mais longos;

- Vídeo como simulação - nesse caso, o vídeo traria a simulação de algum experimento que não pode ser feito em sala, devido ao perigo ou a exigência de tempo e recurso. Por exemplo, algum documentário que demonstre experimento químico ou o crescimento de uma planta;

- Vídeo como conteúdo de ensino - informa sobre determinado assunto, podendo permitir abordagem interdisciplinar. Nessa situação, podem se usados tutoriais ou entrevistas;

- Vídeo como produção - aquele que é produzido pelos professores e/ou estudantes e pode possuir diferentes finalidades: documentar um evento; modificar algum material já produzido; e desenvolver a expressão dos alunos;

- Vídeo como avaliação - para avaliar o processo de aprendizagem;

- Vídeo-espelho - para que o aluno e o professor possam se ver na tela, e examinar suas qualidades e defeitos;

- Vídeo como integração/suporte de outras mídias - se refere a relacionar o vídeo com diferentes mídias, como televisão, computador, telefone.

Sendo assim, é imprescindível que ocorra um planejamento por parte do professor, para que ele defina qual a melhor forma de se utilizar o vídeo a fim de alcançar o objetivo proposto. De acordo com Ribeiro et al. (2016, p. 4175),

O vídeo deve ser utilizado através de um planejamento minucioso para garantir e proporcionar resultados significativos na transmissão didática dos conteúdos, pois quando explorado de forma organizada, o recurso tecnológico potencializa aulas interessantes, dinâmicas e participativas, tornando-se uma fonte de informação alternativa, possibilitando ao aluno conhecer outras realidades, levantar questionamentos, além de construir seu próprio conhecimento, ajudado pelo direcionamento do professor.

Dessa forma, temos que o vídeo se apresenta como um recurso didático promissor, contudo muitos docentes possuem dificuldades em utilizá-lo de maneira a potencializar o aprendizado. Segundo Rizzo Junior (2011), apesar de termos um aumento no uso desse recurso em sala de aula, ele ocorre devido à presença do mesmo no cotidiano de professores e alunos, da aquisição de equipamentos pela escola (televisão, DVD, etc.), e do interesse dos professores em utilizá-lo. Esse mesmo autor ressalta que não há “[...] uma política de formação para o uso do audiovisual presente nas grades curriculares dos cursos cujos egressos se tornam profissionais da Educação Básica” 
(RIZZO JUNIOR, 2011, p. 12), ou seja, os docentes vão para o campo de atuação sem terem formação técnica e didática para utilizar esse recurso com seus alunos. Em geral, os cursos de formação de professores trabalham pouco a criatividade dos docentes para o uso desse e de outros recursos didáticos, reduzindo o olhar do novo professor para o modelo dito tradicional de aulas, no qual se prioriza as aulas expositivas.

Além disso, de acordo com Silva (2011, p. 38), “[...] é preciso dar aos professores reais e efetivas condições materiais, estruturais e financeiras para que eles tenham disponibilidade de planejar, incorporar e avaliar o uso dessas novas ferramentas ao seu fazer docente". Ou seja, para potencializar os processos de ensino e de aprendizagem, é necessário não só o planejamento de como utilizar o vídeo, mas também uma estrutura viável para empregar esse recurso didático.

Porém, é preciso considerar que as tecnologias, incluindo os vídeos, modificam o dia a dia dos alunos e transformam o seu modo de interpretar o mundo (MORAIS, 2000). Assim, é necessário que o professor saiba como incorporar essa tecnologia em sua prática pedagógica, pois, de acordo com Serafim e Sousa (2011, p. 20), a forma como o docente utiliza essa tecnologia "[...] depende, em parte, de como ele entende esse processo de transformação e de como ele se sente em relação a isso, se ele vê todo esse processo como algo benéfico, que pode ser favorável ao seu trabalho, ou se ele se sente ameaçado e acuado por essas mudanças". Logo, se o docente não identifica o vídeo como um recurso pedagógico, sua utilização nas aulas poderá se tornar apenas passatempo para os alunos.

Sendo assim, para que o docente se sinta preparado a trabalhar com esses recursos, deve buscar "[...] capacitação e aperfeiçoamento na área das tecnologias quanto ao uso pedagógico desses novos recursos de ensinar e aprender, devido à constatação de que nos cursos de graduação, pouco, ou quase nada ainda, está sendo proposto aos futuros professores" (CANTINI et al., 2006, p. 877), ou seja, é necessário que se tenha uma formação continuada para esses profissionais.

Para Moran (1995, p. 27), “O vídeo ajuda a um professor, atrai os alunos, mas não modifica substancialmente a relação pedagógica". Desta forma, segundo o autor, ele atua diretamente na sensibilização dos alunos, podendo agir de forma positiva ou negativa, dependendo da mediação do docente. Caso o professor não consiga utilizar o vídeo de forma a despertar o interesse do aluno, esse recurso audiovisual não atingirá nenhuma função didática, podendo, ao contrário do desejado, criar nos estudantes certa resistência ao seu uso.

Diante disso, o trabalho que realizamos consistiu em investigar, a partir das perspectivas de estudantes de cursos de licenciatura de uma Universidade Federal localizada na Zona da Mata mineira, de que modo o vídeo tem sido utilizado como recurso didático na formação de professores da Educação Básica. Mais especificamente, objetivamos analisar como os futuros professores compreendem o papel do vídeo enquanto um recurso didático; além de identificar diferentes usos de 
vídeo na sala de aula de cursos de licenciatura da referida Universidade; e refletir sobre como os estudantes de licenciaturas têm sido formados para o uso de vídeos na sua prática educativa.

\section{METODOLOGIA}

$\mathrm{Na}$ pesquisa que deu origem a este artigo, investigamos de que modo o vídeo tem sido utilizado como recurso didático na formação de professores da Educação Básica. Por não estarmos preocupados com a representatividade quantitativa dos dados, mas sim com o quão significativos eles se mostram para compreender o fenômeno em questão, é que adotamos a abordagem qualitativa de pesquisa (ALVES-MAZZOTTI; GEWANDSZNAJDER; 2004; BORBA; ARAÚJO, 2004; BOGDAN; BIKLEN, 1999). Acreditamos que essa perspectiva metodológica melhor se enquadra aos objetivos desta pesquisa, pois nela não nos interessamos em medir ou quantificar o uso do vídeo nas aulas dos cursos de licenciatura, mas sim investigar aquilo que se mostrou, para nós, particular e significativo. Nosso olhar se voltou para os modos, os usos, as crenças, os sentimentos, as concepções dos estudantes acerca de um determinado fenômeno (no caso, uso do vídeo na formação inicial docente). Tais elementos são de tamanha subjetividade e complexidade que exigiu de nossa parte uma descrição detalhada que pudesse favorecer uma análise atenta e rigorosa.

Para participarem desta investigação, foram escolhidos estudantes de diferentes licenciaturas que estivessem cursando disciplinas nas quais o docente utilizasse o vídeo em suas aulas. Para isso, foi realizada, previamente, uma conversa com alguns professores que lecionavam disciplinas para as licenciaturas, a fim de saber se faziam uso de vídeos nas disciplinas que ministravam. A partir disso, selecionamos duas disciplinas distintas, na qual estavam matriculados estudantes de diferentes cursos. Em seguida, os estudantes dessas disciplinas foram convidados a participarem da pesquisa e, os que aceitaram, foram divididos em três grupos, sendo que os estudantes de cada grupo pertenciam ao mesmo curso de licenciatura e, na ocasião, cursavam uma mesma disciplina.

Cabe destacar que a produção de dados ocorreu nos anos de 2017 e 2018, antes da pandemia ocasionada pela COVID-19, com estudantes que cursavam as disciplinas de forma presencial. Logo, suas falas e perspectivas não levam em conta o contexto de ensino remoto vivenciado em $2020 \mathrm{e}$ 2021.

Os procedimentos de produção dos dados definidos para a realização dessa pesquisa consistiram em entrevistas semiestruturadas feitas com os três grupos de estudantes. Um grupo foi 
formado por cinco estudantes do curso de Pedagogia - Laura ${ }^{5}$, Carla, Daniele, Sofia e André - que cursavam a disciplina Fundamentos da Educação Especial I, oferecida como obrigatória apenas para este curso. Outro grupo, formado por dois alunos do curso de Letras - Marília e Augusto - que cursavam uma disciplina optativa para vários cursos chamada Estudos Culturais e Educação: docência e cinema. E, finalmente, um terceiro grupo formado por três estudantes do curso de História - Eliana, João e Valmir - os quais também cursavam a disciplina Estudos Culturais e Educação: docência e cinema. Todos os estudantes já haviam concluído, pelo menos, $70 \%$ da carga horária de seu respectivo curso. Durante as entrevistas, eles foram questionados sobre o modo como os seus professores utilizavam o vídeo em sala de aula; qual a opinião deles sobre essa utilização do vídeo; e se eles se sentiam preparados para trabalhar com essa tecnologia em uma futura prática docente.

As entrevistas foram gravadas em áudio para posterior transcrição e análise. Para Rosa e Arnoldi (2006, p. 87), esse método de produção de dados permite “[...] a obtenção de grande riqueza informativa - intensiva, holística e contextualizada - por serem dotadas de um estilo especialmente aberto [...]". Utilizamos a entrevista semiestruturada, pois "[...] o questionamento é mais profundo e, também, mais subjetivo, levando ambos [entrevistador e entrevistado] a um relacionamento recíproco, muitas vezes, de confiabilidade".

Organizamos e sistematizamos os dados, para efeito de análise, concomitantemente ao processo de sua produção, pois esta fase da pesquisa requereu idas e vindas que auxiliaram no esclarecimento dos fatos. Segundo Alves-Mazzotti e Gewandsznajder (2004, p. 170) o processo de análise é "[...] complexo, não-linear, que implica um trabalho de redução, organização e interpretação dos dados que inicia já na fase exploratória e acompanha toda a investigação".

As entrevistas foram ouvidas diversas vezes para que pudéssemos produzir uma transcrição das falas dos futuros professores, na qual fossem evidenciadas apenas os depoimentos que atendessem aos objetivos da pesquisa. Com essa transcrição em mãos, produzimos uma narrativa que possibilitou a obtenção de um texto mais descritivo, permitindo que estabelecêssemos um diálogo com as falas dos estudantes e buscássemos um aporte teórico que fundamentasse tal diálogo. Esse processo foi longo e exigiu um envolvimento profundo das pesquisadoras com os dados. A partir deste movimento, buscamos atender aos objetivos traçados e às nossas indagações de pesquisa, as quais questionavam sobre o modo como o vídeo tem sido utilizado nos cursos de formação de professores na visão dos estudantes de licenciaturas.

\footnotetext{
${ }^{5}$ Os nomes utilizados são fictícios, a fim de preservar a identidade dos entrevistados.
} 


\section{A VISÃO DOS FUTUROS PROFESSORES SOBRE O USO DO VÍDEO NA FORMAÇÃO DOCENTE}

Tendo em vista que o nosso objetivo foi investigar de que modo o vídeo tem sido utilizado como recurso didático, na visão de estudantes de licenciaturas de uma Universidade Federal de Minas Gerais, identificamos, com base nas entrevistas realizadas, três temas emergentes dos dados: 1) a utilização do vídeo em sala de aula, onde evidenciamos como os docentes de cursos de licenciaturas desta Universidade fazem uso do vídeo; 2) as potencialidades e limitações do vídeo como recurso didático, parte na qual discorremos sobre como os estudantes entendem essa tecnologia; e 3) a formação para o uso do vídeo como instrumento pedagógico, onde abordamos sobre a preparação que os futuros professores possuem para utilizar essa tecnologia.

\section{UTILIZAÇÃO DO VÍDEO EM SALA DE AULA}

Diante das entrevistas realizadas com os estudantes de diferentes cursos de uma mesma Universidade, podemos levantar alguns pontos importantes sobre como o vídeo tem sido utilizado pelos formadores de professores em sala de aula. Percebemos que, na maioria das vezes, os professores se preocupam em utilizar o vídeo como um recurso auxiliar na formação dos licenciandos. Augusto relatou que, no curso de Letras, muitos professores usam pequenos vídeos para ilustrar um conteúdo, apresentando-os após a explicação teórica. Marília complementa que, ao se estudar uma outra Língua, os filmes ou clipes costumam ser empregados para se avaliar a compreensão auditiva dos alunos.

No caso do curso de Pedagogia, Laura e Carla afirmaram que havia professores que traziam o vídeo para simular uma situação que poderia acontecer nas escolas e, a partir dele, pediam que respondessem a um roteiro, no qual deviam sugerir formas de se trabalhar diante de tal episódio. Além disso, André apontou que alguns professores usavam o filme para iniciar um debate, no qual questões do conteúdo eram discutidas.

Da mesma forma, os estudantes do curso de História também apresentavam experiências positivas com o vídeo. Eliana contou que alguns professores empregavam filmes para ilustrar um fato histórico e, por meio dele, se iniciava uma discussão sobre tal acontecimento, e Valmir completa que outros traziam pequenos documentários como prévia do assunto a ser tratado, a fim de despertar a curiosidade dos estudantes e iniciar um novo tema.

Assim, notamos que os professores das licenciaturas utilizam o vídeo em suas aulas de diferentes maneiras, que vão ao encontro das categorias apresentadas por Moran (1995): vídeo 
como sensibilização, como ilustração, como simulação, como conteúdo de ensino e como avaliação. Isso permitiu, segundo os entrevistados, que as aulas se tornassem mais dinâmicas e que os estudantes pudessem participar de forma ativa nos processos de ensino e aprendizagem, como vemos na fala de Laura: "Com o vídeo, a aula não fica na mesmice. Ele serve para iniciar o debate, onde todos participam. Fica mais fácil debater tendo as imagens e falas do vídeo como suporte”, o que aponta que alguns estudantes podem acreditar que os usos de recursos audiovisuais fazem com que a aula pareça menos tradicional, uma vez o professor não se utiliza apenas recursos que são usuais.

No entanto, os estudantes da Pedagogia relataram que o uso de vídeo tem sido feito com mais frequência nas disciplinas optativas do curso, o que revela que não eram, necessariamente, todos os estudantes que tinham contato com esse recurso didático ao longo da graduação. Talvez, o uso desse recurso nas disciplinas optativas se relacione com o fato de elas serem compostas por uma quantidade menor de estudantes, o que favorece o planejamento de atividades nas quais toda a turma participe de forma mais ativa.

Além disso, João relatou que um de seus professores utiliza o vídeo sem um objetivo aparente. De acordo com ele: "Parecia que o professor não preparava a aula. Um dia ele não foi dar aula e pediu para uma aluna colocar o filme. Vimos o filme, e só. Na aula seguinte ele não perguntou nada do filme, não pediu para fazermos nada... Achei uma perda de tempo”.

Nesse caso, temos que a utilização do vídeo constituiu em um ato não pedagógico, ou seja, ele foi utilizado apenas para preencher o tempo da aula, o que, de acordo com Betetto (2011), não deve acontecer, visto que o vídeo, na maioria das vezes, está relacionado apenas com o entretenimento e pouco com a aprendizagem. Utilizar tal recurso sem objetivo pedagógico reforça essa ideia. Além disso, o fato do estudante considerar tal prática como "perda de tempo" vai ao encontro do que Moran (1995) apresenta: que o vídeo, por si só, não proporciona aprendizagem. Para que isso ocorra, ele deve ser mediado pelo professor em sua prática docente.

\section{POTENCIALIDADES E LIMITAÇÕES DO VÍDEO COMO RECURSO DIDÁTICO}

Outro ponto abordado nas entrevistas se referiu a como os estudantes avaliavam o uso do vídeo em suas aulas. Todos os entrevistados falaram que ele pode ser um recurso didático importante e ressaltaram seus aspectos positivos. Sofia e João afirmaram que, com os vídeos, ficava mais fácil relacionar o assunto dos textos com o que se debatia em sala de aula, além de favorecer a associação entre a discussão teórica e a prática. André ressaltou que o vídeo ajudava a entender o conteúdo, pois, algumas vezes, a explicação do professor ficava vaga ou não era totalmente compreensível. Desse modo, o vídeo vinha para ilustrar o que tinha sido dito, colaborando a 
compreensão. Além disso, Marília e Daniela relataram que o vídeo ajudava a despertar o interesse pelo que se estava sendo ensinado, pois era algo que chamava a atenção e despertava curiosidade.

Isso reitera o que autores como Silva e Oliveira (2010), Santos e Kloss (2010), Moran (1995) e Betetto (2011) acreditam. Todos eles, veem no vídeo um aliado à prática docente, capaz de favorecer os processos de ensino e de aprendizagem, uma vez que com ele é possível se trabalhar a criatividade do aluno; desenvolver sua visão crítica; facilitar o entendimento dos conteúdos e conceitos; e despertar a curiosidade e o interesse dos estudantes por novos temas. Além disso, esse recurso permite que o estudante aproxime os temas aprendidos à sua realidade.

Por outro lado, Carla chamou a atenção que, para o vídeo ser um recurso didático capaz de colaborar com a aprendizagem do estudante, ele deve ter um propósito. De acordo com ela, “o uso do vídeo tem que ter um propósito, porque se for passar só para preencher o tempo, não ajuda em nada. Se forem passados sem uma intenção, sem planejamento, não adianta”.

Com isso, nos remetemos à importância de se fazer um planejamento detalhado ao se utilizar o vídeo em aula, fato que Ribeiro et al. (2016) e Moran (1995) sustentam. Esses autores afirmam que ao utilizar esse recurso didático, o professor precisa ter uma intencionalidade, precisa saber como vai utilizá-lo e como vai avaliar seu uso. Caso contrário, não influenciará na aprendizagem dos estudantes. Assim, temos que o vídeo deve ser um recurso que venha a contribuir para a significação dos conteúdos, portanto, ele, por si só, não deve ser o conteúdo e nem substituir a aula ou o professor.

Os estudantes também foram questionados se utilizariam tal recurso em suas aulas, futuramente. Todos eles afirmaram que gostariam muito de usar, por acreditarem que o uso do vídeo pode potencializar a aprendizagem. André assegurou que utilizaria e enfatizou que o filme pode ser analisado sob vários aspectos de acordo com o objetivo proposto, e "se for um filme que o aluno goste, pode facilitar ainda mais a associação com o conteúdo”.

Marília ainda observou que, no caso do ensino de outras línguas, os vídeos ajudam a entender o vocabulário. Esses comentários reforçam a ideia de que o filme, aliado ao trabalho docente, pode promover uma aprendizagem mais significativa por parte dos estudantes. Como ressaltou André, os filmes são uma fonte rica de conhecimento, do qual se podem explorar diferentes aspectos e conteúdos, fazendo com que o aluno aprenda de forma divertida e interessante.

Porém, os estudantes também levantaram algumas limitações. Daniele e Laura afirmaram que usariam se a escola tivesse estrutura para tal fim; Sofia concordou, e acrescentou que faria uso do vídeo se a escola disponibilizasse um espaço próprio para isso, pois, muitas vezes, "a escola não tem sala de vídeo e só tem um datashow e um notebook. Ai, quando vamos usar, já está reservado para alguém, ou não está funcionando”. De fato, é importante que a escola forneça os recursos 
necessários para que o professor utilize vídeos em suas aulas, assim como afirma Silva (2011). A falta de estrutura para tal fim e a indisponibilidade dos equipamentos, se apresentam como limitadores para o planejamento do trabalho docente tendo em vista que, em algumas escolas, são disponibilizados apenas um aparelho de projeção para utilização por todos os docentes. No entanto, é importante ressaltar que a reserva dos equipamentos faz parte do planejamento do professor. $\mathrm{O}$ vídeo não deve ser visto como um recurso de última hora, seu uso deve ser pensado previamente, o que proporciona ao professor tempo hábil para reservar os aparelhos necessários e, caso outro docente já vá utilizá-lo, ainda há a possibilidade para se replanejar.

Valmir apresentou uma perspectiva diferente, ao relatar que "tentaria utilizar uma vez, mas, se os alunos não se interessassem, eu não empregaria mais esse recurso". A visão desse estudante reflete o comportamento de muitos professores, que fazem uso do vídeo uma vez e, caso algo não saia como planejado, desistem de utilizar essa tecnologia. Porém, o uso de recursos audiovisuais em sala de aula consiste em algo que é construído, que se aprimora com a prática. Para isso, Betetto (2011) evidencia a importância de se avaliar a utilização desse recurso, ou seja, é preciso que o docente reflita sobre como o vídeo foi utilizado, o que funcionou e o que não atingiu o objetivo proposto. É importante identificar o que não deu certo, e isso deve servir para o crescimento profissional do professor. Deste modo, o docente conseguirá aperfeiçoar suas aulas e planejar a utilização dessa tecnologia de forma a favorecer a aprendizagem de seus estudantes.

\section{FORMAÇÃO PARA O USO DO VÍDEO COMO INSTRUMENTO PEDAGÓGICO}

De acordo com Rizzo Júnior (2011), muitos docentes sentem dificuldades em utilizar o vídeo em suas aulas. Esse fato se mostrou verdadeiro em nossa pesquisa. Ao serem questionados se sentiam-se preparados para utilizar o vídeo em suas aulas, oito em 10 estudantes relataram que não se viam totalmente preparados, mas que, por já terem feito uso desse recurso durante os estágios, se sentiam um pouco mais confiantes para utilizá-lo. Isso pode ser visto nas falas da Carla e da Eliana, ao revelarem que:

A primeira vez que usei [o vídeo] no estágio fiquei um pouco insegura, pois ninguém na escola usava. Não sabia muito bem como fazer, pois nunca tive uma formação voltada para isso. Ai tentei pensar em como meus professores usavam, como eu achava que era mais legal, e tentei repetir isso lá. Deu bem certo. (Carla, Pedagogia).

Usar vídeo parece fácil, mas não é. A não ser que você queira só preencher o tempo mesmo. Usei com meus alunos no estágio, mas foi dificil planejar como ia fazer isso. Pensei em um jeito que eu achava que seria bom, mas na hora não deu muito certo. Com a prática, fui tentando outras possibilidades." (Eliana, História). 
Esses relatos sugerem a importância do professor buscar por capacitação para uso dessa tecnologia, uma vez que, de acordo com Cantini et al. (2006), ao longo da graduação se tem pouca ou nenhuma formação para empregar tais recursos. Em geral, os estudantes de licenciaturas não cursam uma disciplina específica que trabalhe como produzir e utilizar os vídeos como instrumento pedagógico. No entanto, a pesquisa de Vaz (2017) relata que parte dos estudantes possui algum tipo de experiência com vídeos, seja na edição de vídeos caseiros ou na produção de materiais audiovisuais para alguma disciplina. Porém, muitos preferem vídeos que apresentem um conteúdo voltado para o entretenimento, que não exigem uma reflexão sobre o que está sendo abordado.

Esse fato sugere que, talvez, a maior necessidade de formação esteja voltada para a questão didática do uso do vídeo, uma vez que dominar a técnica nem sempre é um problema para parte significativa dos estudantes. Assim, eles acabam por reproduzir aquilo que seus professores fazem, sem sentir a necessidade de refletir sobre o que está sendo feito, sem avaliar o processo e sem a preocupação de desenvolver metodologias distintas.

Logo, o depoimento de Carla evidencia a importância de os docentes de licenciaturas utilizarem, de forma planejada, o vídeo como recurso didático em suas aulas, uma vez que os futuros professores tendem a repetir com seus alunos as experiências positivas que tiveram ao longo de sua trajetória escolar. Da mesma forma, tendem a não repetir as metodologias que consideraram ineficientes. Ou seja, se os formadores de professores utilizarem o vídeo apenas como forma de entretenimento ou para preencher o tempo de suas aulas, é provável que os estudantes não utilizem essa tecnologia futuramente, uma vez que dificilmente a perceberão como um recurso pedagógico significativo. Nessa perspectiva, Marília mostrou que também se espelha no trabalho feito por seus professores: "Quando dou aula, faço como meus professores. Me baseio naquilo que eles fizeram e que eu acho legal. Sempre dá certo”.

Diante desses discursos, notamos que a forma como o docente apresenta os vídeos em suas aulas, influencia no modo como os futuros professores irão utilizá-los, o que corrobora a ideia de Serafim e Souza (2011), ao relatarem que a importância que o professor imprime a essa tecnologia, depende do modo como ele a enxerga. Porém, é preciso evidenciar que os docentes formadores podem ser referências para os futuros professores, contudo, é preciso que o estudante não se apegue apenas a isso, e busque formação que atenda às demandas específicas do seu ambiente de trabalho. Além disso, Laura enfatizou a importância de se planejar antes de fazer uso de vídeos, como notamos em sua fala à seguir: "Olha, não sei se posso afirmar que estou pronta, com certeza. Mas consigo utilizar sim, desde que planeje bem antes, e pense em outras possibilidades caso a estratégia inicial não dê certo”. Nessa mesma direção, Betetto (2011) afirma que um planejamento 
detalhado é fundamental para que o vídeo favoreça a aprendizagem dos estudantes, pois permite que esse recurso seja pensado a fim de agregar de modo qualitativo à prática do docente.

Por fim, André ressaltou que seria importante ter uma formação específica que ensinasse diferentes formas de se utilizar essa tecnologia. Ele acredita que:

\section{[...] falta no curso uma formação especifica para isso. Tem até uma disciplina optativa, que eu não fiz, que acho que fala sobre isso. Mas seria legal se nós aprendêssemos outras formas de usar o vídeo, ou até mesmo dicas de como produzir um, para fazermos com os alunos (André, Pedagogia).}

Desse modo, concordamos com André que seria relevante que os cursos de formação de professores oferecessem uma disciplina obrigatória que abordasse a temática das tecnologias digitais, em particular dos recursos audiovisuais, na qual os alunos pudessem não só discutir sobre a importância ou papel do vídeo e as diferentes formas de utilizá-lo no ensino, mas que também tivessem a oportunidade de produzir e editar vídeos, a fim de usarem essa metodologia com seus estudantes, futuramente. Nesse sentido, Vaz (2017) afirma que os estudantes tendem a se interessar em técnicas de edição de vídeo. Porém, para ser utilizado como recurso pedagógico, é preciso que eles percebam as potencialidades dos vídeos, reflitam sobre diferentes formas de usá-lo e, além disso, tenham um olhar criativo perante ele, tanto para produzi-lo quanto para utilizá-lo. Logo, seria ideal uma disciplina que oferecesse formação técnica, didática e incentivasse o desenvolvimento da criatividade.

Sendo assim, percebemos que os futuros professores reconhecem as possibilidades da utilização de vídeos em sala de aula, porém, sentem falta de uma formação específica que os apresente possibilidades diferentes e promova vivências para utilização desse recurso didático, fazendo com que baseiem suas práticas no que foi experienciado ao longo da formação.

\section{CONSIDERAÇÕES FINAIS}

Esse artigo objetivou discutir, a partir da visão de futuros professores, como o vídeo tem sido utilizado em cursos de licenciaturas de uma Universidade Federal localizada no interior de Minas Gerais, bem como analisar a compreensão que os estudantes possuem a respeito desse recurso didático-pedagógico.

Por meio da análise das entrevistas, notamos que os estudantes de licenciaturas que participaram da pesquisa acreditam que o vídeo é uma tecnologia que pode favorecer os processos de ensino e aprendizagem, porém, ainda se mostram receosos em utilizá-la, uma vez que não tiveram disciplinas que abordassem sobre o uso de tal recurso, ao longo da graduação. Além disso, 
eles apontam as dificuldades de empregar recursos audiovisuais em algumas escolas, pois nem sempre há estrutura física adequada para tal fim e nem equipamento disponível para todos os professores.

Os dados sugerem, ainda, que a falta de formação específica faz com que o futuro professor reproduza as metodologias vivenciadas ao longo de sua trajetória escolar e acadêmica, o que ressalta a importância dos professores de cursos de licenciaturas se atentarem para o modo como planejam e utilizam as tecnologias e, mais especificamente os vídeos, em suas aulas, dado que seus alunos tendem a repetir, futuramente, as situações de ensino pelas quais passaram.

Diante disso, concluímos que seria importante que os cursos de formação de professores dessem mais ênfase para a utilização dos recursos audiovisuais e ressaltassem a importância de emprega-los em sala de aula. No caso do vídeo, particularmente, seria desejável que os futuros professores aprendessem não só a parte técnica e didática, mas que aprimorassem sua visão criativa e reflexiva.

É importante ressaltar que o uso de tecnologia digital em sala de aula, de modo geral, não é algo fácil de se fazer. Necessita tempo de planejamento e avaliação, e se modifica de acordo com a turma na qual se está. Sendo assim, o docente que busca melhorar sua prática e aprimorá-la com o uso de recursos audiovisuais, deve persistir no seu propósito, destacando as vivências positivas e aprendendo com as negativas; caminhando, dessa forma, para o desenvolvimento de metodologias de ensino que favoreçam a produção de conhecimento pelos estudantes.

Por fim, como já destacado, essa pesquisa foi realizada antes da pandemia ocasionada pela COVID-19. Diante disso, acreditamos que a temática aqui abordada se mostra ainda mais relevante em um momento no qual o ensino remoto tornou-se um princípio importante para manter o vínculo entre estudantes e profissionais da Educação nos diferentes níveis de ensino, apesar de suas limitações (ARRUDA, 2020). Portanto, é fundamental que outras pesquisas sobre o uso educacional de vídeos sejam realizadas, uma vez que, no atual contexto, a utilização de tecnologias digitais foi intensificada. Assim, é possível que a visão e as experiências que os futuros professores possuem em relação ao uso de vídeos nas aulas tenha se ressignificado, exigindo, portanto, novas análises as quais podem ser entrelaçadas com os resultados apresentados nesse artigo.

\section{REFERÊNCIAS}

Alves-MaZzotTi, A. J.; GEWANDSZNAJDER, F. O Método nas Ciências Naturais e Sociais: pesquisa quantitativa e qualitativa. 2. ed. São Paulo: Pioneira, 2004.

ARRUDA, E. P. Educação Remota Emergencial: elementos para políticas públicas na educação brasileira em tempos de Covid-19. EmRede - Revista De Educação a Distância, 7(1), 257-275. 
Disponível em: https://www.aunirede.org.br/revista/index.php/emrede/article/view/621. Acesso em: 20 fev. 2021.

BORBA, M. C.; ARAUJO, J. L. (Org) Pesquisa Qualitativa em Educação Matemática. Belo Horizonte: Autêntica, 2004.

BETETTO, J. R. O uso do vídeo como recurso pedagógico: conceitos, questões e possibilidades no contexto escolar. 2011. 71 f. Trabalho de Conclusão de Curso (Graduação em Pedagogia) Universidade Estadual de Londrina, Londrina. 2011. Disponível em: https://www. uel.br/ceca/pedagogia/pages/arquivos/JOELMA\%20RIBEIRO\%20BETETTO. Acesso em: $10 \mathrm{dez}$. 2016.

BOGDAN, R.; BIKLEN, S. Investigação Qualitativa em Educação: uma introdução à teoria e aos métodos. Portugal: Porto Editora, 1999.

CANTINI, M. C.; BORTOLOZZO, A. R. S.; FARIA, D. S.; FABRÍCIO, F. B. V.; BASZTABIN, R.; MATOS, E. O Desafio do Professor Frente as Novas Tecnologias. Educere, 2006. Disponível em:https://www.pucpr.br/eventos/educere/educere2006/anaisEvento/docs/CI-081-TC Acesso em: 10 dez. 2016.

CASTRO, S. B. O Uso do Vídeo como Recurso Didático na Formação de Professores sob a Ótica dos Docentes Formadores. Relatório Final, referente ao período de março/2017 a fevereiro/2018, apresentado à Universidade Federal de Viçosa, como parte das exigências do PROBIC/FAPEMIG.

CASTRO, S. B. Entrelaçamentos entre a Formação Docente para o Ensino de Matemática e o Uso das Tecnologias Digitais nos Cursos de Pedagogia. Dissertação (Mestrado em Educação) Universidade Federal de Viçosa, Viçosa, 2020.

MORAIS, G. M. S. Novas Tecnologias no Contexto Escolar. Comunicação \& Educação, São Paulo, [18]: 15 a 21, maio/ago. 2000.

MORAN, J. M. O Vídeo na Sala de Aula. Comunicação \& Educação. Ed. Moderna, [2]: 27 - 35. São Paulo, 1995. Disponível em: https://extensao.fecap.br/artigoteca/Art_015. Acesso em: 10 dez. 2016.

MORAN, J. M; MASETTO, M. T.; BEHRNS, M. A. Novas tecnologias e mediação Pedagógica. Campinas: Papirus, 2006.

RIBEIRO, E. B.; FERNANDES, E. F.; ALVES,J. Z.; ABREU, A. R.; SILVA, J. D. G.; DANTAS, F. K. S.; ABREU, M. K. F. O uso do vídeo como Recurso Didático: Percepção dos alunos de biologia sobre a influência desse recurso para a aprendizagem. In: VI Enebio e VIII Erebio Regional 3. n. 9. p. 4174- 4184. Anais... Brasil: Associação Brasileira de Ensino de Biologia, 2016. Disponível em: http://www.sbenbio.org.br/wordpress/wp-content/uploads/renbio-9/pdfs/2177.pdf Acesso em: 26 fev. 2018.

RIZZO JUNIOR, S. A. Educação audiovisual: uma proposta para a formação de professores de Ensino Fundamental e de Ensino Médio no Brasil. 2011. 150 p. Tese (Doutorado) - Escola de Comunicações e Artes, Universidade de São Paulo, 2011.

ROSA, M. V. F. P. C.; ARNOLDI, M. A. G. C. A Entrevista na Pesquisa Qualitativa: mecanismos para validação dos resultados. Belo Horizonte: Autêntica, 2006. 
SANTOS, P. R.; KLOSS, S. A Criança e a Mídia: a importância do uso do vídeo em escolas de Joaçaba - SC. Intercom - XI Congresso da Comunicação na Região Sul, Novo Hamburgo, RS, 2010. Disponível em: https://www.intercom.org.br/papers/regionais/sul2010/resumos/R20-0957 -1 Acesso em: 10 dez. 2016.

SERAFIM, M. L.; SOUSA, R. P. Multimídia na Educação: o vídeo digital integrado ao contexto escolar. In: SOUSA, R.P.; MIOTA, F.M.C.S.C.; CARVALHO, A.B.G.(Org) Tecnologias digitais na educação [online]. Campina Grande: EDUEPB, 2011. Disponível em: http:// books.scielo.org/id/6pdyn/02. Acesso em: 20 set. 2017.

SILVA, A. M. O Vídeo como Recurso Didático no Ensino de Matemática. 2011. 198 f. Dissertação (Mestrado em Educação em Ciências e Matemática) - Universidade Federal de Goiás, Goiânia, 2011. Disponível em: https://mestrado.prpg.ufg.br/up/97/o/Diss_051.pdf. Acesso em: 25 out. 2017.

SILVA, M. Sala de aula interativa. Rio de Janeiro: Quartet, 2000.

SILVA, R. V.; OliveIRA, E. M. As Possibilidades do Uso do Vídeo como Recurso de Aprendizagem em Salas de Aula do $5^{\circ}$ Ano. V EPEAL - Pesquisa em Educação: Desenvolvimento, Ética e Responsabilidade Social, 2010. Disponível em: https:// dmd2.webfactional.com/media/anais/POSSIBILIDADE-DEVIDEOCOMORECURSO-DE-APREN DIZAGEM-EM-SALAS-DE-AULA-DE-5-SERIE Acesso em: 10 dez. 2016.

VAZ, R. T. O Processo de Produção de Vídeos Educativos a Partir de uma Experiência com Licenciandos de Pedagogia. 2017. Dissertação (Mestrado em Educação) - Universidade Federal de Viçosa, Viçosa, MG, 2017. 